\title{
Geographical distribution of drinking-water with high iodine level and association between high iodine level in drinking-water and goitre: a Chinese national investigation
}

\author{
Hongmei Shen*, Shoujun Liu, Dianjun Sun, Shubin Zhang, Xiaohui Su, Yanfeng Shen and Hepeng Han \\ The Center for Endemic Disease Control, Chinese Center for Disease Control and Prevention, Harbin Medical University, \\ 157 Baojian Road, Harbin 150081, Heilongjiang Province, Peoples's Republic of China
}

(Received 17 August 2010 - Revised 12 November 2010 - Accepted 17 December 2010 - First published online 15 February 2011)

\section{Abstract}

Excessive iodine intake can cause thyroid function disorders as can be caused by iodine deficiency. There are many people residing in areas with high iodine levels in drinking-water in China. The main aim of the present study was to map the geographical distribution of drinking-water with high iodine level in China and to determine the relationship between high iodine level in drinking-water and goitre prevalence. Iodine in drinking-water was measured in 1978 towns of eleven provinces in China, with a total of 28857 water samples. We randomly selected children of 8-10 years old, examined the presence of goitre and measured their urinary iodine in 299 towns of nine provinces. Of the 1978 towns studied, 488 had iodine levels between 150 and $300 \mu \mathrm{g} / \mathrm{l}$ in drinking-water, and in 246 towns, the iodine level was $>300 \mu \mathrm{g} / \mathrm{l}$. These towns are mainly distributed along the original Yellow River flood areas, the second largest river in China. Of the 56751 children examined, goitre prevalence was $6.3 \%$ in the areas with drinking-water iodine levels of $150-300 \mu \mathrm{g} / 1$ and $11.0 \%$ in the areas with drinking-water iodine $>300 \mu \mathrm{g} /$ l. Goitre prevalence increased with water and urinary iodine levels. For children with urinary iodine $>1500 \mu \mathrm{g} / \mathrm{l}$, goitre prevalence was 3.69 times higher than that for those with urinary iodine levels of $100-199 \mu \mathrm{g} / \mathrm{l}$. The present study suggests that drinking-water with high iodine levels is distributed in eleven provinces of China. Goitre becomes more prevalent with the increase in iodine level in drinking-water. Therefore, it becomes important to prevent goitre through stopping the provision of iodised salt and providing normal drinking-water iodine through pipelines in these areas in China.

Key words: High iodine: Drinking-water: Endemic goitre

Iodine is an essential micronutrient of the thyroid hormone. Both insufficient and excessive iodine intake can cause thyroid hormone disorders. Iodised salt has been widely distributed in many countries including China to prevent disorders caused by iodine deficiency. However, excessive iodine intake may cause thyroid goitre, overt hyper- and hypothyroidism, subclinical hyper- and hypothyroidism, autoimmune thyroid disease, iodine allergies and iodine poisoning, loss of intelligence, etc. ${ }^{(1-5)}$. Sources of iodine are naturally found in food and water. Japan was the first country to discover food-source goitre in the world about 40 years ago. Suzuki et al. ${ }^{(6)}$ reported that Hokkaido fishermen had a high prevalence of goitre because of over-consumption of seaweed, and school-aged children had a prevalence of 6.8-8.9\%. After this report in Japan, China also reported iodine-excess goitre cases in $1980^{(7)}$. These cases were related to over-eating 'kelp salt', which contained iodine levels as high as $226 \cdot 5-1382 \mathrm{mg} / \mathrm{kg}$. Zimmermann et al. $^{(8)}$ also found that high dietary intakes of iodine in children result in high thyroid volume.

China was the first country to report water-source iodineexcess goitre cases. A high prevalence of goitre was found among fisherman in Hebei Province in the 1970s. Following these findings, a series of epidemiological and clinical investigations and animal experiments were conducted in the province. Zhao et al. ${ }^{(9)}$ reported that water iodine level was very high, i.e. $661.2 \mu \mathrm{g} / \mathrm{l}$ in a deep well (about $600-700 \mathrm{~m}$ ), and goitre was more prevalent among 4344 fishermen who drank the water compared with those who did not (28.36 v. 8.37\%). Between 1984 and 2003, other provinces in China also reported water-related iodine-excess goitre cases. Goitre prevalence was from $10 \cdot 84$ to $73 \%$, and median urinary iodine was from 586.7 to $2428.5 \mu \mathrm{g} / \mathrm{l}^{(10,11)}$. Zhao et al. ${ }^{(12)} \mathrm{stu}$ died 2471 individuals in twelve towns of the Jiangsu Province, China, and reported that townships with a higher median level of iodine in well water had a higher median urinary iodine

Abbreviation: RR, relative risk.

*Corresponding author: H. Shen, fax +86 451 86657674, email shenhm119@126.com 
concentration, prevalence of goitre and abnormal thyroid volume.

Iodine-deficiency disorder has been primarily controlled in China through widely providing iodised salt. With this prevention strategy, the challenge is how to prevent goitre in populations who reside in areas with high levels of iodine in drinking-water. Therefore, we conducted a Chinese national investigation to identify the geographical distribution of drinking-water with high iodine levels in China. We conducted physical measurements for goitre and urinary iodine among children aged 8-10 years to determine the relationship between high iodine levels in drinking-water and goitre prevalence.

\section{Experimental methods}

\section{Water sample collections and iodine level measurement}

We included all 129 counties that were suspected to have high levels of water iodine in eleven provinces (i.e. Anhui, Beijing, Fujian, Hebei, Henan, Jiangsu, Inner Mongolia, Shandong, Shanxi, Tianjin and Xinjiang), based on previous investigations and results of national iodine-deficiency disorder monitoring. In these counties, each of the 1978 towns was divided into five districts (i.e. east, west, south, north and centre). From each district, one village was randomly selected. For villages with less than five wells, we collected water samples from all available wells. For those with more than five wells, the village was divided into five areas (i.e. east, west, south, north and centre), and one well was randomly selected from each area for those with more than one well. In the village where water was provided through pipelines, we collected a sample from the source of the water supply. In total, we collected 28857 water samples from the 1978 towns. In addition to high iodine content, drinking-water in these areas meets China Standards for Drinking Water Quality.

Water samples were stored in $50 \mathrm{ml}$ plastic bottles and kept in a refrigerator maintained at $4{ }^{\circ} \mathrm{C}$. The bottles were washed twice with water samples before sampling. Iodine level was examined within a week after the sample collection. Water iodine was determined using the As-Ce catalytic spectrophotometric method for high water iodine. Considering the high level of iodine in the water samples, we adopted the China Iodine Deficiency Disorder Laboratory standard for iodine measurement. Validity of the measurement was assessed using standardised samples from the China External Quality Control.

\section{Physical measurement for determining goitre}

Study population. Based on the analysis of water iodine levels, the towns were categorised into three groups: those with median water iodine $<150,150-300$ and $>300 \mu \mathrm{g} / \mathrm{l}$. The categories were determined by the national standard 'Determination and Classification of the Areas of High Water Iodine and the Endemic Areas of Iodine Excess Goiter ${ }^{\text {(13), }}$ stating that iodine goitre is more likely to occur in areas with median water iodine $>300 \mu \mathrm{g} / \mathrm{l}$, uncertain in areas with $150-300 \mu \mathrm{g} / \mathrm{l}$ and less likely to occur in areas with $<150 \mu \mathrm{g} / \mathrm{l}$.

Due to limited financial and time resources, physical measurement for goitre was conducted among children aged 8-10 years during 2005 and 2006, mainly in towns with a median water iodine of $150-300 \mu \mathrm{g} / \mathrm{l}$ and in some towns with median water iodine $>300 \mu \mathrm{g} / \mathrm{l}$. Towns with median water iodine $<150 \mu \mathrm{g} / \mathrm{l}$ were not included. A total of 277 towns with iodine levels of $150-300 \mu \mathrm{g} / \mathrm{l}$ and twenty-two towns with iodine levels $>300 \mu \mathrm{g} / \mathrm{l}$ were randomly selected from nine provinces (i.e. Anhui, Beijing, Hebei, Henan, Jiangsu, Inner Mongolia, Shandong, Shanxi and Tianjin).

Each town was divided into five districts (i.e. east, south, west, north and centre). In each district, one primary school was randomly selected if there was more than one school. From each primary school, forty children (twenty boys and twenty girls) aged 8-10 years were randomly selected to examine the thyroid. For those schools with less than forty students aged 8-10 years, all were included.

The present study was conducted according to the guidelines laid down in the Declaration of Helsinki, and all procedures involving human subjects were approved by the Ethics Committee of the Center for Endemic Disease Control, Chinese Center for Disease Control and Prevention. Verbal informed consent was obtained from all subjects, and the consent was witnessed by teachers and formally recorded by investigators.

Goitre determination and urine iodine level measurement. Physicians who were working at provincial and municipal centres for disease control examined the randomly selected children. All physicians had been working at the Centre for Disease Control, specifically for domestic disease diagnosis and treatment. Therefore, they had rich experience in examining the thyroid. Before the study, the physicians were further trained and examined some children in order to reduce physician variation in identifying goitre. Examination was made by two physicians, separately; when the results were inconsistent, they would reconsider. The diagnosis was made based on the Chinese national standard 'diagnostic criteria for endemic goiter $^{\text {,(14) }}$ and WHO/UNICEF/ICCIDD ${ }^{(15)}$-recommended criteria. Because of limited budget, goitre in 56575 children in 299 towns was determined by palpation. We identified children with goitre through measuring thyroid volume by ultrasound among 1413 children in fifteen towns of Tianjin. Goitre prevalence identified by ultrasound was similar to that identified by palpation, 10.33 and $11.25 \%$, respectively.

Goitre is graded according to the following classification:

Grade 0: no palpable or visible goitre.

Grade 1: a goitre that is palpable but not visible when the neck is in the normal position (i.e. the thyroid is not visibly enlarged). (A thyroid gland will be considered goitrous when each lateral lobe has a volume greater than the terminal phalanx of the thumbs of the subject being examined.) Thyroid nodules in a thyroid, which is otherwise not enlarged, fall into this category.

Grade 2: a swelling in the neck that is clearly visible when the neck is in a normal position and is consistent with an enlarged thyroid when the neck is palpated. 
It is recommended that a total goitre rate (number with goitres of grades 1 and 2 divided by total number examined) of $5 \%$ or more in schoolchildren $6-12$ years of age be used to signal the presence of a public health problem.

From the participants, we collected the middle portion of the urine (not less than $5 \mathrm{ml}$ ) in dry and clean polyethylene or glass tubes, sealed tightly to prevent evaporation. The urine samples were stored in a refrigerator maintained at $4^{\circ} \mathrm{C}$ and analysed within 1 month. Urinary iodine was determined in accordance with the China health standard 'Method for determination of iodine in urine by $\mathrm{As}^{3+}-\mathrm{Ce}^{4+}$ catalytic spectrophotometry ${ }^{,(16)}$. Validity of measurement was assessed using the quality-control samples from the China External Quality Control.

The WHO/UNICEF/ICCIDD ${ }^{(15)}$ have recommended the following epidemiological criteria for assessing iodine nutrition based on median urinary iodine concentrations in schoolaged children: $<100 \mu \mathrm{g} / \mathrm{l}$, insufficient; $100-199 \mu \mathrm{g} / \mathrm{l}$, adequate; 200-299 $\mu \mathrm{g} / \mathrm{l}$, above requirements; $\geq 300 \mu \mathrm{g} / \mathrm{l}$, excessive.

\section{Statistical analyses}

Descriptive statistics were employed to describe the geographical distribution. The Spearman rank correlation was used for testing the correlation between goitre and water iodine and urine iodine levels. The relative risk (RR) for goitre was calculated across urinary iodine levels.

\section{Results}

There were 488 towns with a median water iodine of $150-300 \mu \mathrm{g} / \mathrm{l}$ and 246 towns with a median water iodine $>300 \mu \mathrm{g} / \mathrm{l}$. These towns were mainly located in the middle of China (Fig. 1). Based on local population reports, 18.87 million resided in areas with water iodine levels of $150-300 \mu \mathrm{g} / 1$ and $12 \cdot 11$ million resided in areas with water iodine $>300 \mu \mathrm{g} / \mathrm{l}$.

Goitre prevalence was 6.33 and $11.03 \%$ among children who resided in towns with a median water iodine of 150-300 and $>300 \mu \mathrm{g} / 1$, respectively (Table 1 ). The prevalence varied across provinces, ranging from 1.22 to $14.35 \%$.

Table 2 and Fig. 2 show the correlation between median water iodine and goitre prevalence. Goitre prevalence increased with the increase in median water iodine. For example, goitre prevalence was $6 \cdot 24 \%$ in the districts with a median water iodine of $150-199 \mu \mathrm{g} / \mathrm{l}$, which was much lower than $15.81 \%$ in the district with median water iodine $>500 \mu \mathrm{g} / \mathrm{l}$.

Table 2 also shows the inter-relationship between water iodine level, urine iodine level and goitre prevalence. Urine iodine level increased with the increase in water iodine level. Goitre prevalence increased with the increase in water iodine and urine iodine levels.

We analysed the relationship between goitre prevalence and median urine iodine. For children with a median urine iodine of $300-399 \mu \mathrm{g} / 1$, goitre prevalence was $5 \cdot 16 \%$, which was slightly higher than the national standard of $5 \%{ }^{(17)}$ and WHO/UNICEF/ICCIDD-recommended criteria $^{(15)}$. Compared with goitre prevalence among children with urine iodine of $100-199 \mu \mathrm{g} / \mathrm{l}$, the RR for goitre increased with the increase in urine iodine: 1.56 for those with urine iodine of $300-$ $399 \mu \mathrm{g} / \mathrm{l} ; 2 \cdot 27$ for those with urine iodine of $600-699 \mu \mathrm{g} / \mathrm{l}$; 3.46 for those with urine iodine of $900-999 \mu \mathrm{g} / \mathrm{l} ; 3.69$ for those with urine iodine of $>1500 \mu \mathrm{g} / \mathrm{l}$.

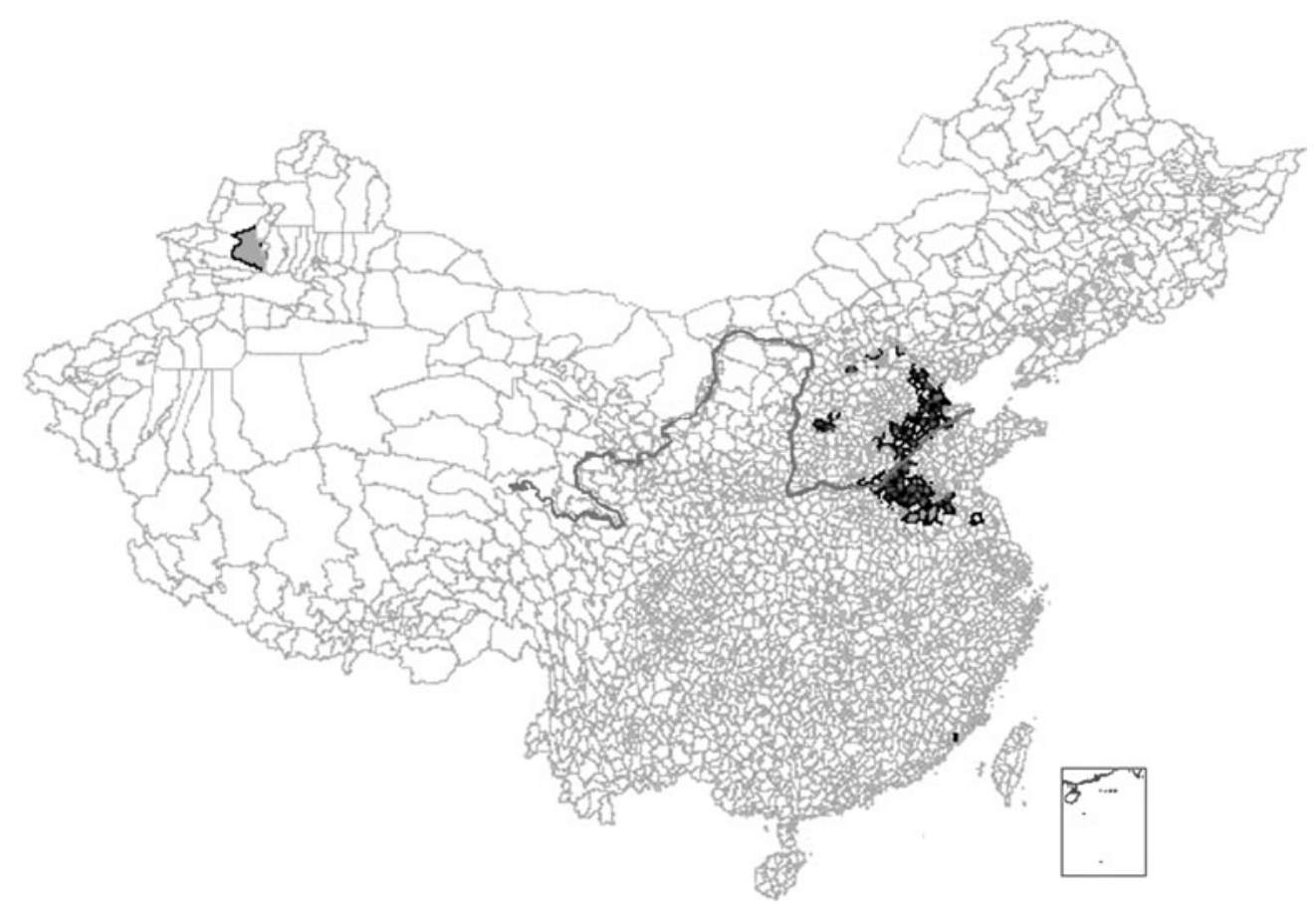

Fig. 1. Geographical distribution of drinking-water iodine (WI) in China. $\square, \mathrm{WI} \geq 300 \mu \mathrm{g} / \mathrm{l}(n 64)$; $\square, 150 \leq \mathrm{WI}<300 \mu \mathrm{g} / \mathrm{l}(n 44)$; $\square$, WI $<150 \mu \mathrm{g} / \mathrm{l}(n 21)$; $>$, Yellow River. 
Table 1. Goitre prevalence and median urine iodine across provinces in China among children aged 8-10 years (Median values, number of towns, children and goitres, and percentages)

\begin{tabular}{|c|c|c|c|c|c|c|c|c|c|c|}
\hline \multirow[b]{3}{*}{ Provinces } & \multicolumn{5}{|c|}{ Water iodine $150-300 \mu \mathrm{g} / \mathrm{l}$} & \multicolumn{5}{|c|}{ Water iodine $>300 \mu \mathrm{g} / \mathrm{l}$} \\
\hline & \multirow[b]{2}{*}{ Towns $(n)$} & \multirow[b]{2}{*}{ Children $(n)$} & \multicolumn{2}{|c|}{ Goitre } & \multirow{2}{*}{$\begin{array}{l}\text { Median urine } \\
\text { iodine }(\mu \mathrm{g} / \mathrm{l})\end{array}$} & \multirow[b]{2}{*}{ Towns $(n)$} & \multirow[b]{2}{*}{ Children $(n)$} & \multicolumn{2}{|c|}{ Goitre } & \multirow{2}{*}{$\begin{array}{l}\text { Median urine } \\
\text { iodine }(\mu \mathrm{g} / \mathrm{l})\end{array}$} \\
\hline & & & $n$ & $\%$ & & & & $n$ & $\%$ & \\
\hline Anhui & 8 & 1592 & 176 & 11.06 & $815 \cdot 69$ & - & - & - & - & \\
\hline Beijing & 1 & 154 & 8 & $5 \cdot 20$ & $520 \cdot 10$ & - & - & - & - & \\
\hline Hebei & 103 & 20969 & 950 & 4.53 & $357 \cdot 70$ & - & - & - & - & \\
\hline Henan & 11 & 937 & 115 & $12 \cdot 27$ & $428 \cdot 50$ & 2 & 92 & 12 & 13.04 & 892.46 \\
\hline Jiangsu & 31 & 6293 & 77 & $1 \cdot 22$ & $598 \cdot 00$ & - & - & - & - & \\
\hline Inner Mongolia & 2 & 209 & 30 & $14 \cdot 35$ & $360 \cdot 18$ & - & - & - & - & \\
\hline Shandong & 92 & 18006 & 1562 & $8 \cdot 67$ & 760.98 & 5 & 998 & 123 & $12 \cdot 32$ & 794.00 \\
\hline Shanxi & 18 & 3724 & 318 & 8.54 & $562 \cdot 70$ & 11 & 2364 & 248 & 10.49 & $1150 \cdot 35$ \\
\hline Tianjin & 11 & 949 & 110 & 11.59 & 462.90 & 4 & 464 & 49 & $10 \cdot 56$ & $566 \cdot 62$ \\
\hline Total & 277 & 52833 & 3346 & $6 \cdot 33$ & $489 \cdot 10$ & 22 & 3918 & 432 & 11.03 & 794.00 \\
\hline
\end{tabular}

\section{Discussion}

This Chinese national investigation demonstrated that high iodine in drinking-water was found in eleven provinces out of thirty-one in China. Approximately 31 million people are living in these high water iodine areas. Seven provinces (Shandong, Hebei, Henan, Tianjin, Jiangsu, Anhui and Shanxi) had extremely high levels of iodine in their drinking-water. We also found that goitre prevalence was correlated with the iodine level in drinking-water and urine among children.

There are three possible reasons for the geographical distribution of high levels of iodine in drinking-water. One possible reason is that the Yellow River caused iodine deposits in the areas through several divesting floodings. The second longest river in China originates in Qinghai Province, in western China, and ends at the Bohai Sea. Currently, the river flows through nine provinces of China, including two high drinking-water iodine provinces of Shandong and Henan. The river has flooded numerous times due to its low basin and has changed its main course a few times historically. High drinking-water iodine areas of Hebei, Jiangsu, Anhui, Tianjin and Beijing used to be courses of the river at some point in time in the past. The distribution indicated that high levels of iodine might be caused by the sediment-laden river. Another possible reason is that changes in the sea coast resulted in iodine being deposited inland. Bohai and Huang Huai Seas are rich in iodine, and their coast lines have

Table 2. Relationship between water iodine, urine iodine, and goitre prevalence among children aged $8-10$ years

(Median values, number of towns, children and goitres, and percentages)

\begin{tabular}{lcccrrr}
\hline & & & & \multicolumn{2}{c}{ Goitre } \\
\cline { 5 - 7 } $\begin{array}{l}\text { Median } \\
\text { iodine }(\mu \mathrm{g} / \mathrm{l})\end{array}$ & $\begin{array}{c}\text { Towns } \\
(n)\end{array}$ & $\begin{array}{c}\text { Children } \\
(n)\end{array}$ & $\begin{array}{c}\text { Median urine } \\
\text { iodine }(\mu \mathrm{g} / \mathrm{l})\end{array}$ & $n$ & $\%$ \\
\hline 150 & 129 & 24407 & $460 \cdot 90$ & 1523 & $6 \cdot 24$ \\
200 & 89 & 16940 & 479.50 & 954 & $5 \cdot 63$ \\
250 & 59 & 11486 & 644.40 & 869 & $7 \cdot 57$ \\
300 & 10 & 1882 & 764.98 & 166 & $8 \cdot 82$ \\
350 & 3 & 515 & 919.40 & 57 & 11.07 \\
400 & 3 & 547 & $791 \cdot 25$ & 55 & $10 \cdot 10$ \\
$>500$ & 6 & 974 & $969 \cdot 80$ & 154 & $15 \cdot 81$ \\
\hline
\end{tabular}

changed several times. Each change has left iodine in the land. The third possible reason is that iodine was leached or eroded down to a low-lying area inland, which was accumulated in the specific area due to a poor drainage system, such as the Shanxi Province.

A cause of goitre is iodine deficiency or excess. In our sample, goitre prevalence was correlated with the level of iodine in drinking-water (correlation coefficient 0.93), and increased with urinary iodine levels. Our analysis of urine iodine further supports that excess iodine contributes to goitre. Goitre prevalence was above 5\% among children with a median urine iodine of $300-399 \mu \mathrm{g} / \mathrm{l}$. This supports the WHO/UNICEF/ICCIDD's cut-off point of excessive iodine intake (i.e. median urine iodine $>300 \mu \mathrm{g} / \mathrm{l}$ ). WHO/ UNICEF/ICCIDD ${ }^{(15)}$ have recommended that iodine nutrition was optimal when median urine iodine was $100-200 \mu \mathrm{g} / \mathrm{l}$. So taking total goitre rate at the time of median urine iodine of $100-200 \mu \mathrm{g} / 1$ as a standard, we calculated the RR of suffering from goitre for children aged 8-10 years with different urinary iodine levels. The RR was more than 1.5 times when median urine iodine was $>300 \mu \mathrm{g} / \mathrm{l}$. The strength of association reached the middle class. The RR was more than $3 \cdot 0$ times when median urine iodine was $>900 \mu \mathrm{g} / \mathrm{l}$. The strength of association reached the strong class. To prevent iodinedeficiency disorders, iodised salt $(35 \pm 15$ parts per million

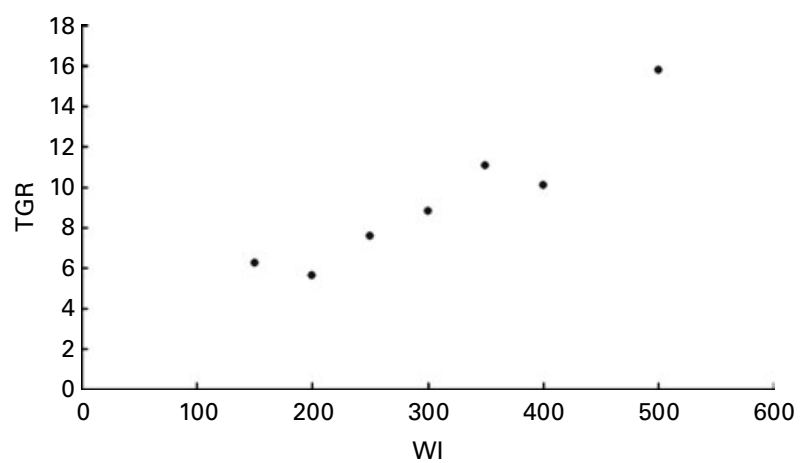

Fig. 2. Relationship of water iodine (WI) level and goitre prevalence among children aged 8 to 10 years. TGR, thyroid goitre prevalence. 
iodine; mean \pm 2 SD) has been provided nationally since 1995 , including the areas with a high level of iodine in drinkingwater. Therefore, iodised salt (may have) facilitated goitre occurrence rather than prevented the disease in areas with high levels of iodine in the water. The present study mapped the geographical distribution of high iodine in drinking-water in China. Based on these findings, the following three preventive recommendations have been provided to the Chinese government: (1) to stop and eliminate the sale of iodised salt in these areas; (2) to change drinking-water and provide pipeline water with an appropriate amount of iodine; (3) monitor drinking-water iodine and goitre occurrence.

The present study has four limitations. First, we conducted this investigation in eleven provinces based on sporadic reports on water iodine level. We may have missed some districts with high levels of iodine in drinking-water. Second, our investigation focused mainly on districts with water iodine levels of $150-300 \mu \mathrm{g} / \mathrm{l}$, and only sampled a few towns with water iodine levels $>300 \mu \mathrm{g} / \mathrm{l}$. Third, some residents in high water iodine districts took iodised salt when we conducted this survey. This might have confounded the effect of water iodine on goitre occurrence. Fourth, we did not assess the agreement among the physicians who conducted the physical examination for detecting goitre. However, we controlled face validity through extensive training.

Despite these limitations, this large Chinese national investigation on water iodine and goitre identified districts with high iodine in drinking-water and demonstrated the relationship between water iodine and goitre prevalence. Our findings provide evidence to prevent goitre in these areas.

\section{Acknowledgements}

This survey was supported by grant from the China Ministry of Health. Thanks are extended to the many people who participated in the investigation, including physicians, children, teachers and government staff. The authors declare that there is no conflict of interest. The contribution of each author was as follows: H. S. participated in the planning of the study, supervision of the investigation, collecting of the data and interpretation of the results. S. L. and D. S. participated in the planning of the study, supervision of the investigation and interpretation of the results. S. Z. and X. S. participated in the supervision of the investigation and collecting the data. Y. S. and H. H. participated in the collection of the data.

\section{References}

1. Yu Z, Zhu H, Chen Z, et al. (1999) Progress in endemic iodine excess goiter (2). Chin J Endemiol 18, 385-387.

2. Bournaud C \& Orgiazzi JJ (2003) Iodine excess and thyroid autoimmunity. J Endocrinol Invest 26, Suppl. 2, 49-56.

3. Teng W, Shan Z, Teng X, et al. (2006) Effect of iodine intake on thyroid diseases in China. N Engl J Med 354, 2783-2793.

4. Li Y, Teng D, Shan Z, et al. (2008) Antithyroid peroxidase and antithyroglobulin antibodies in a five-year follow-up survey of population with different iodine intakes. J Clin Endocrinol Metab 93, 1751-1757.

5. Liu HL, Lam LT, Zeng Q, et al. (2009) Effect of drinking water with high iodine concentration on the intelligence of children in Tianjin. China. J Public Health 31, 32-38.

6. Suzuki H, Higuchi T, Sawa K, et al. (1965) Endemic coast goiter in Hokkaido Japan. Acta Endocrinol 5, 165-170.

7. Yu Z \& Ma T (1980) Endemic iodine excess goiter. Chin Med J 60, 475-479.

8. Zimmermann MB, Ito Y, Hess SY, et al. (2005) High thyroid volume in children with excess dietary iodine intakes. $\mathrm{Am}$ J Clin Nutr 81, 840-844.

9. Zhao J, Guo C, Yu Z, et al. (1987) The study of prevalence law and distribution for the high water iodine endemic goiter in Hebei. China Prev Med 21, 296-299.

10. Yu Z, Zhu H, Chen Z, et al. (1999) Progress in endemic iodine excess goiter (1). Chin J Endemiol 18, 301-303.

11. Liu Y, Zhao L, Zhang J, et al. (2003) Preliminary exploration on children's iodine excess goiter in Dangshan county. Chinese J Ctrl Endem Dis 18, 361-362.

12. Zhao J, Wang P, Shang L, et al. (2000) Endemic goiter associated with high iodine intake. Am J Public Health 90 , $1633-1635$.

13. Liu D, Zhao J, Zhu H, et al. (2003) Determination and classification of the areas of high water iodine and the endemic areas of iodine excess goiter. National Standard of China, GB/T19380-2003.

14. Liu S, Chen Z, Jia Q, et al. (2007) Diagnostic criteria for endemic goiter. Health Standard of China, WS276-2007.

15. WHO, ICCIDD \& UNICEF (2007) Assessment of Iodine Deficiency Disorders and Monitoring their Elimination: A Guide for Programme Managers, 3rd ed. Geneva: WHO.

16. Yan Y, Zhang Y, Liu L, et al. (2006) Method for determination of iodine in urine by $\mathrm{As}^{3+}-\mathrm{Ce}^{4+}$ catalytic spectrophotometry. Health Standard of China, WS/T107-2006.

17. Zhang Y, Chen Z, Ge P, et al. (2008) Criteria for elimination of iodine deficiency disorders. National Standard of China, GB16006-2008. 